\title{
An analysis of neonatal mortality in a tertiary care hospital over a decade - 2008 to 2017
}

\author{
*Medha Weerasekera ${ }^{1}$, Sathika Amarasekara ${ }^{2}$, H V D N Siriwardhane ${ }^{3}$
}

Sri Lanka Journal of Child Health, 2019; 48(4): 326-333

\begin{abstract}
Objective: To evaluate the trends, age at death, causes and birth weights of neonatal deaths from 2008 to 2017 in a tertiary care centre in Sri Lanka.
\end{abstract}

Method: All neonatal deaths from 2008 to 2017 were included in the analysis.

Results: During this 10-year period, there have been 181 neonatal deaths. Male deaths $(54.1 \%, \mathrm{n}=98)$ outnumbered female deaths. Majority $(62.9 \%)$ were early neonatal deaths and $45.6 \%$ of them had died within the first 24 hours of birth. The leading causes of deaths were extreme prematurity (46.4\%), congenital malformations, neonatal respiratory distress syndrome, birth asphyxia and septicaemia. Low birth weight was a significant risk factor for the increased neonatal mortality.

Conclusions: Perinatal mortality rate (PNMR) showed a downward trend except in the last two years of the study period. The neonatal mortality rate (NMR) is lower than the national figures and is well below the global and south Asian figures. Majority (63\%) were early neonatal deaths with $45.6 \%$ dying within first 24 hours of birth. Leading causes of deaths were extreme prematurity, congenital malformations, respiratory distress syndrome, birth asphyxia and septicaemia.

DOI: http://dx.doi.org/10.4038/sljch.v48i4.8827

(Keywords: Neonatal death, Neonatal mortality rate, prematurity, congenital malformation)

${ }^{1}$ Consultant Neonatologist, ${ }^{2}$ Senior Registrar in Neonatology, ${ }^{3}$ Registrar in Paediatrics, Sri Jayewardenepura General Hospital, Nugegoda, Sri Lanka

*Correspondence: medhaweerasekera@gmail.com (iD)

orcid.org/ 0000-0001-5065-1889

(Received on 03 March 2019: Accepted after revision on 26 April 2019)

The authors declare that there are no conflicts of interest

Personal funding was used for the project.

Open Access Article published under the Creative

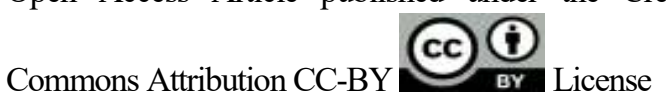

\section{Introduction}

Neonatal period is the most vulnerable time for a child's survival ${ }^{1}$. Globally, 2.9 million neonatal death occur annually and this accounts for $44 \%$ of the under 5-year mortality ${ }^{2}$. Most of these deaths occur within the first week of $\operatorname{life}^{2}$. Around one million deaths occur within the first day of life and nearly another million deaths occur within the next 6 days of life ${ }^{1}$. The average global rate of neonatal deaths during 2017 was 18 per 1000 live births ${ }^{1}$. Vast majority of neonatal deaths occur in low and middle income countries and regionally, the neonatal mortality rate (NMR) is highest in Sub Saharan Africa and South Asia with each estimated at 27 deaths per 1000 live births in $2017^{1}$.

Sri Lanka is an exception to the neighbours in the region and has shown a steady decline in perinatal and neonatal mortality over several decades ${ }^{4}$. However, from 2000-2017, NMR has declined at a slower pace ${ }^{1,4}$. The NMR in 2017 was 5.8 per 1000 live births and a considerable proportion of these deaths are preventable ${ }^{4,5}$. Globally, annual deaths are attributable to three main aetiologies, namely, prematurity (1.0 million), intrapartum asphyxia ( 0.7 millions) and infections $(0.6 \text { millions })^{2}$. Small for gestational age due to intrauterine growth retardation (IUGR) or prematurity, alone or in combination is the risk factor for more than $80 \%$ of neonatal deaths ${ }^{2}$. Boys have a higher biological risk of neonatal death than girls ${ }^{2}$.

The Millennium Development Goals (MDGs) have been associated with remarkable progress for maternal and child deaths, but neonatal mortality reduction has progressed about $30 \%$ slower $^{2,6}$. The country specific Every Newborn Action Plan (ENAP) target is 3.4 neonatal deaths per 1000 live births by 2025 and Sustainable Development Goal (SDG) target $<2.2$ per 1000 by $2030^{7}$. Thus, analysis of each neonatal death with regard to causes, timing and trends in NMR is of paramount importance in order to scale up interventions and fine tune neonatal care.

\section{Objectives}

The objective of this review was to analyse all neonatal deaths at Sri Jayewardenepura General Hospital (SJGH) with regards to age at death, causes and birth weight and to assess the trends in NMR and perinatal mortality rate (PNMR) from 2008 to 2017. 


\section{Method}

All neonatal deaths are documented in the Admission and Death registers of the neonatal intensive care unit (NICU) of SJGH in detail. The birth statistics and stillbirth details were obtained from the birth and stillbirth registers in the labour ward of SJGH. Ethical approval was obtained from the Ethics Review Committee of SJGH. Approval from the head of the institution was obtained to publish the data.

The analysis of the data was done by descriptive statistics with percentages and proportions.
Comparisons were done by Chi-square test and significant $p$ value considered as $<0.05$.

\section{Results}

The total numbers of live births and neonatal deaths from 2008 to 2017 were 39,330 and 181 respectively. From 2012 to 2016 there has been a sustained reduction of neonatal deaths (Figure 1). The trend in NMR is lower than the national figures and is well below the global and south Asian figures $^{5}$. However, the NMR of the institution lies above that of developed countries except in 2011 and 2016. (United States and Europe) $)^{5}$ (Figure $2 \&$ Table 1).

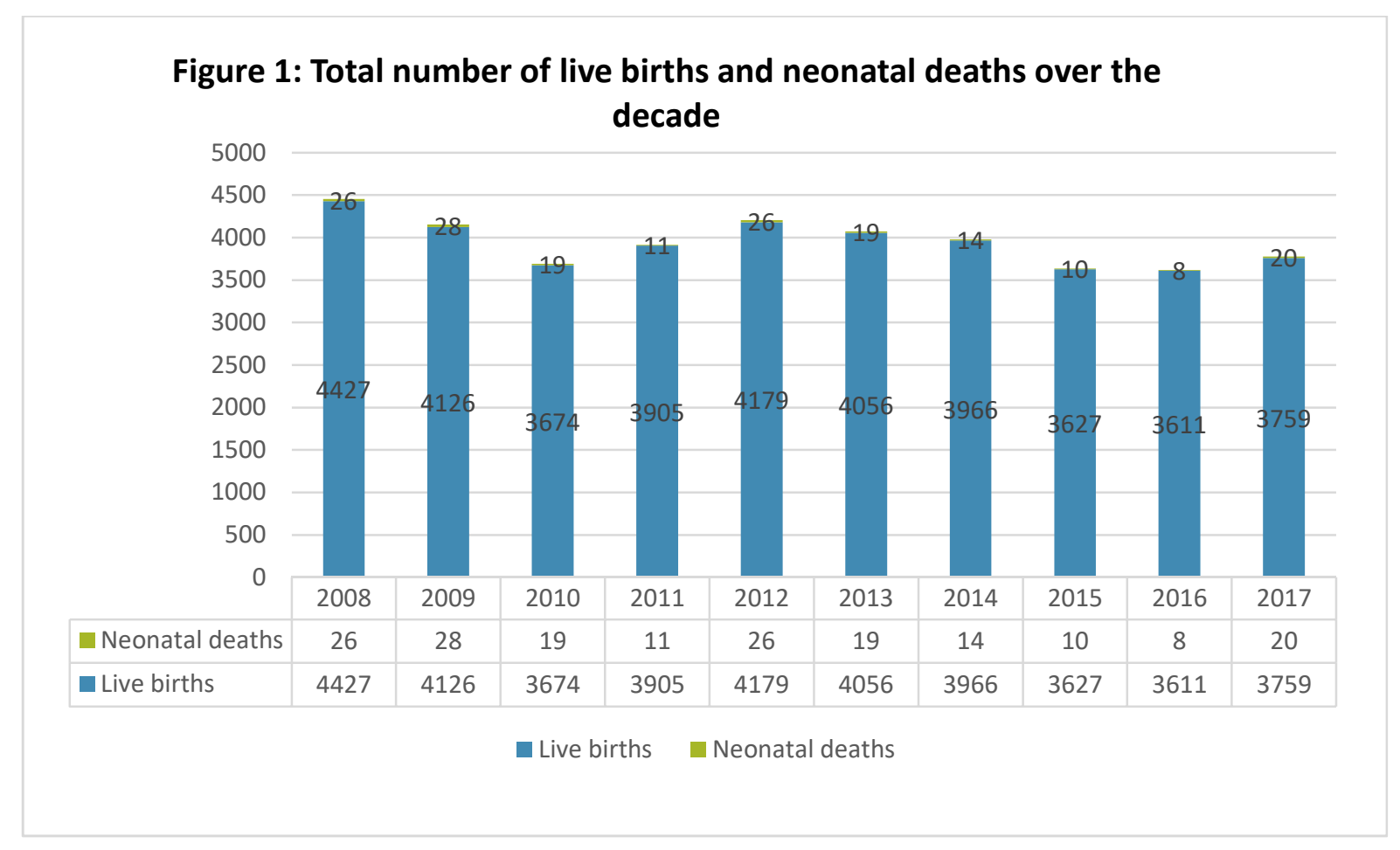

Table 1: Total number of neonatal deaths and NMR from 2008 to 2017 compared to national regional and global figures ${ }^{3}$

$\begin{array}{|llllll|}\text { Year } & \text { NND } & \text { NMR/SJGH } & \text { NMR/SL } & \text { NMR/Asia } & \text { NMR/Global } \\ 2008 & 26 & 5.8 & 7.1 & 35.7 & 23.6 \\ 2009 & 28 & 6.7 & 6.7 & 34.6 & 22.8 \\ 2010 & 19 & 5.1 & 6.4 & 33.6 & 22.1 \\ 2011 & 11 & 2.8 & 6.3 & 32.5 & 21.4 \\ 2012 & 26 & 6.2 & 6.5 & 31.4 & 20.8 \\ 2013 & 19 & 4.6 & 6.5 & 30.4 & 20.1 \\ 2014 & 14 & 3.5 & 6.4 & 29.3 & 19.6 \\ 2015 & 10 & 2.7 & 6.3 & 28.2 & 19 \\ 2016 & 08 & 2.2 & 6.1 & 27.2 & 18.5 \\ 2017 & 20 & 5.3 & 5.8 & 26.3 & 18 \\ \text { Total } & 181 & & & & \\ & & & & \end{array}$


Figure 2:Trends in neonatal mortality rate

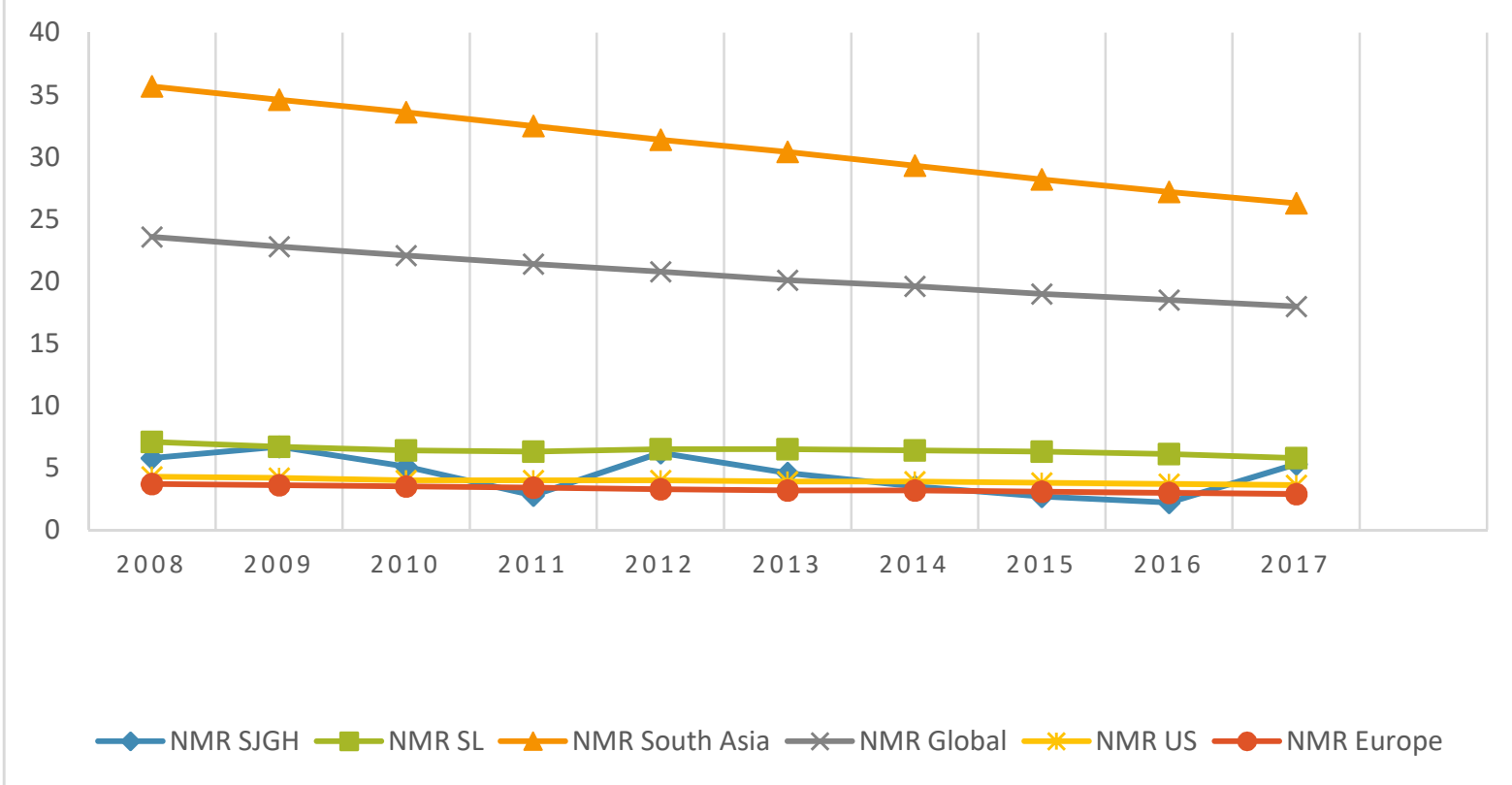

Perinatal mortality rate (PNMR) during the period of analysis showed a downward trend except in the last two years of the study period (Figure 3). During the period of analysis, the total number of male infant deaths $(54.1 \%, \mathrm{n}=98)$ outnumbered the female infant deaths (Figure 4).

Figure 3: The trends in perinatal mortality rate from 2008 to 2017

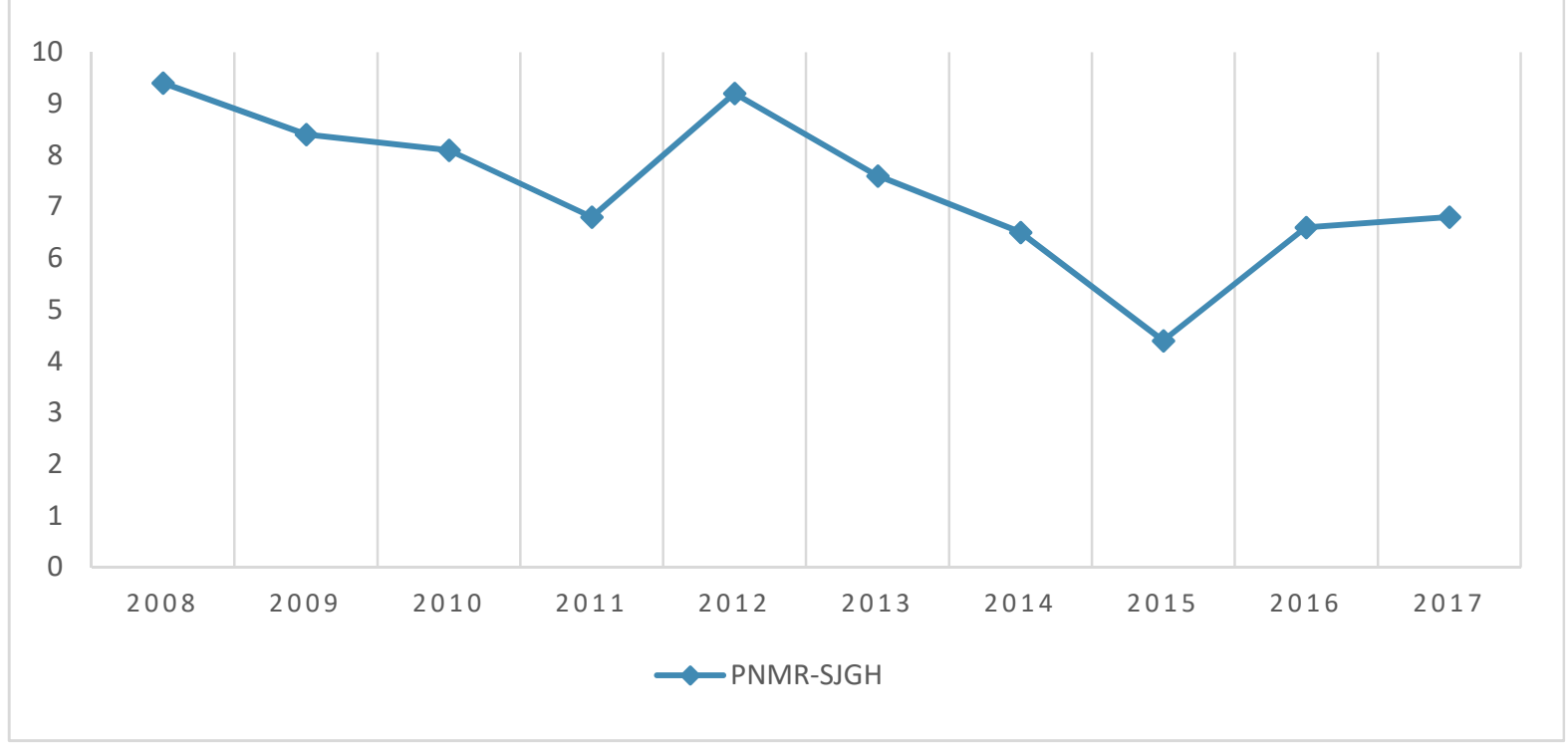




\section{Figure 4: Neonatal deaths according to the gender}

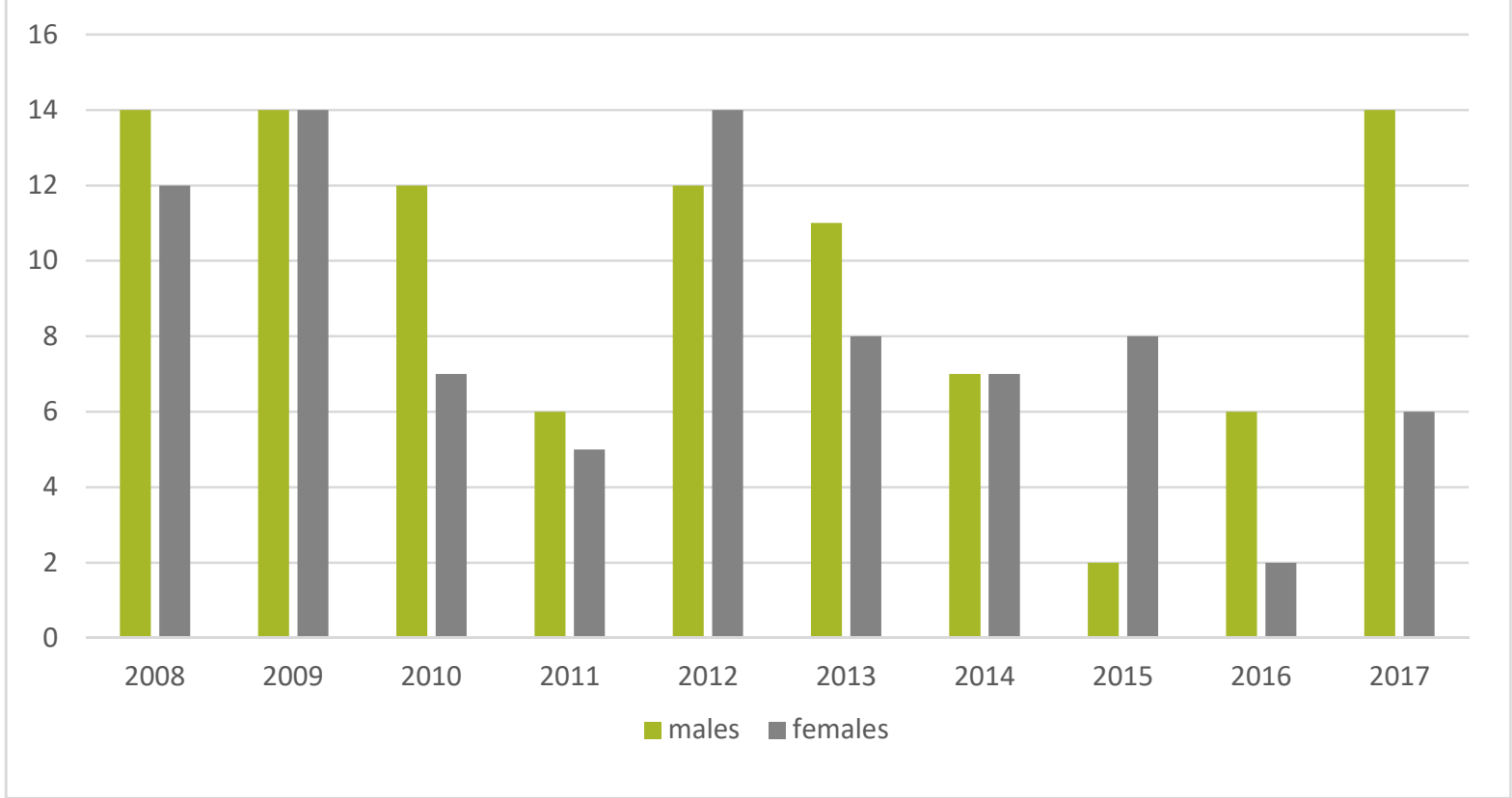

Except in 2017, early neonatal deaths outnumbered late neonatal deaths during the study period (Figure $5)$. Thus, the majority $(\mathrm{n}=114,62.9 \%)$ were early neonatal deaths and $45.6 \%$ of them $(n=52)$ had died within first 24 hours of birth.

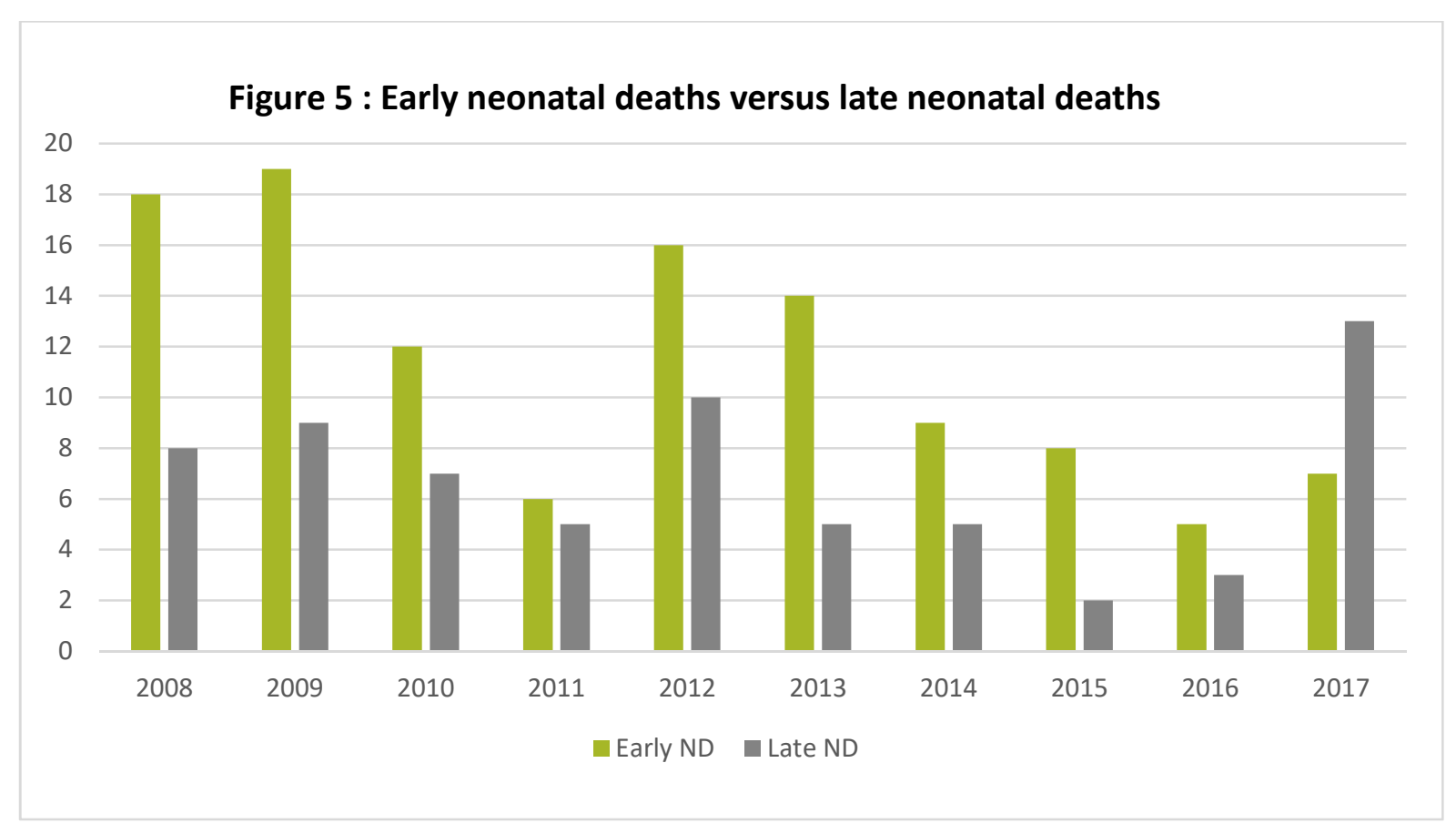

Classification of causes of neonatal deaths was done according to WHO-South East Asia Regional neonatal - perinatal database $\left(\right.$ SEAR-NPD) ${ }^{8}$. The causes of neonatal deaths are classified under ten causes: perinatal asphyxia, birth trauma, extreme prematurity, hyaline membrane disease (HMD)/neonatal respiratory distress syndrome (NRDS), intraventricular haemorrhage, pneumonia/ septicaemia/meningitis, tetanus neonatorum, congenital malformations, other causes (causes not belonging to above categories) and unestablished causes $^{8}$. Most of the deaths $(n=84,46.4 \%)$ were due to extreme prematurity. The other causes in decreasing order of frequency were congenital malformations $(26.5 \%)$, perinatal asphyxia $(9.9 \%)$, NRDS / (HMD) (8.3\%), sepsis (4.9\%) and IVH (1.6\%) (Figure 6). 


\section{Figure 6: causes of deaths}

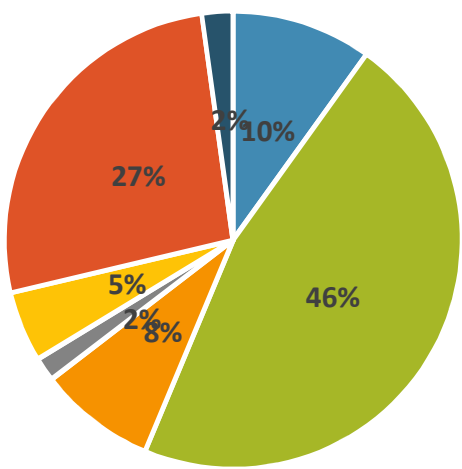

$$
\begin{aligned}
& \text { - Perinatal asphyxia - Extreme prematurity } \\
& \text { - NRDS/HMD } \\
& \text { - Intraventricular haemorrhage (IVH) } \\
& \text { - Pneumonia/septicaemia/meningitis - Congenital malformations } \\
& \text { - Other }
\end{aligned}
$$

There is a marked variation in frequency of causes of neonatal deaths over the years. Even though a reduction of deaths due to extreme prematurity has been observed during the study period, in 2017 the frequency has increased. There is no significant change in deaths due to intrapartum asphyxia and congenital malformations. Interestingly, during the last 3 years of the study, no deaths had occurred due to septicaemia (Figure 7).

\section{Figure 7: Distribution of causes of deaths over the decade}

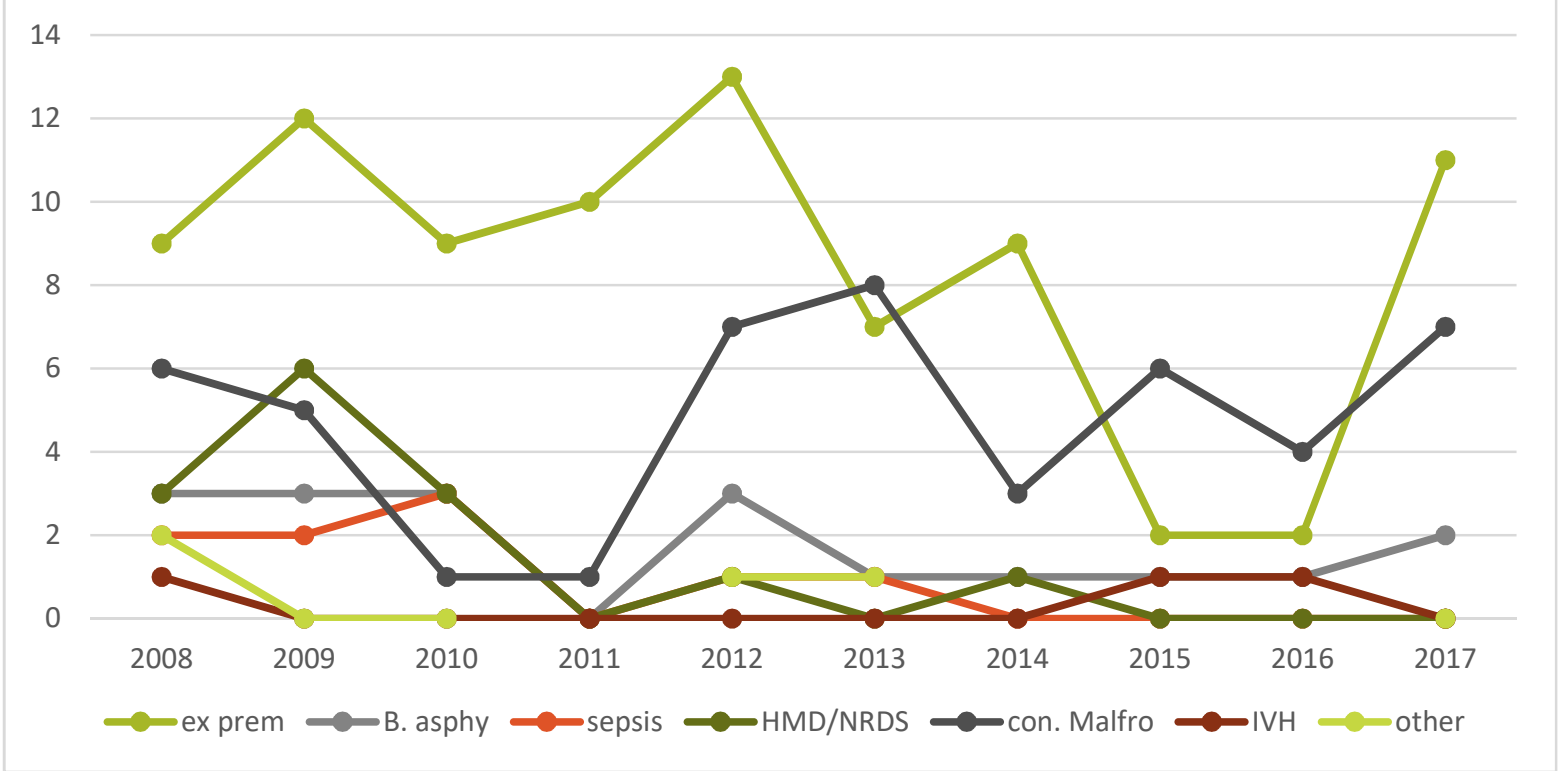

Of the congenital anomalies, complex congenital heart disease accounts for most of the deaths (Figure 8 ). Other anomalies in decreasing order of frequency were respiratory, craniofacial, syndromes, defects of multiple organs, and renal anomalies. Of the seven babies who died due to syndromes, 4 were clinically compatible with trisomy 18 and the other two were severe osteogenesis imperfecta and asphyxiating thoracic dystrophy.

We analysed the deaths according to the birth weight for eight years' duration (Table 4 and Figure 9). The smaller the baby at birth higher the risk of death. 


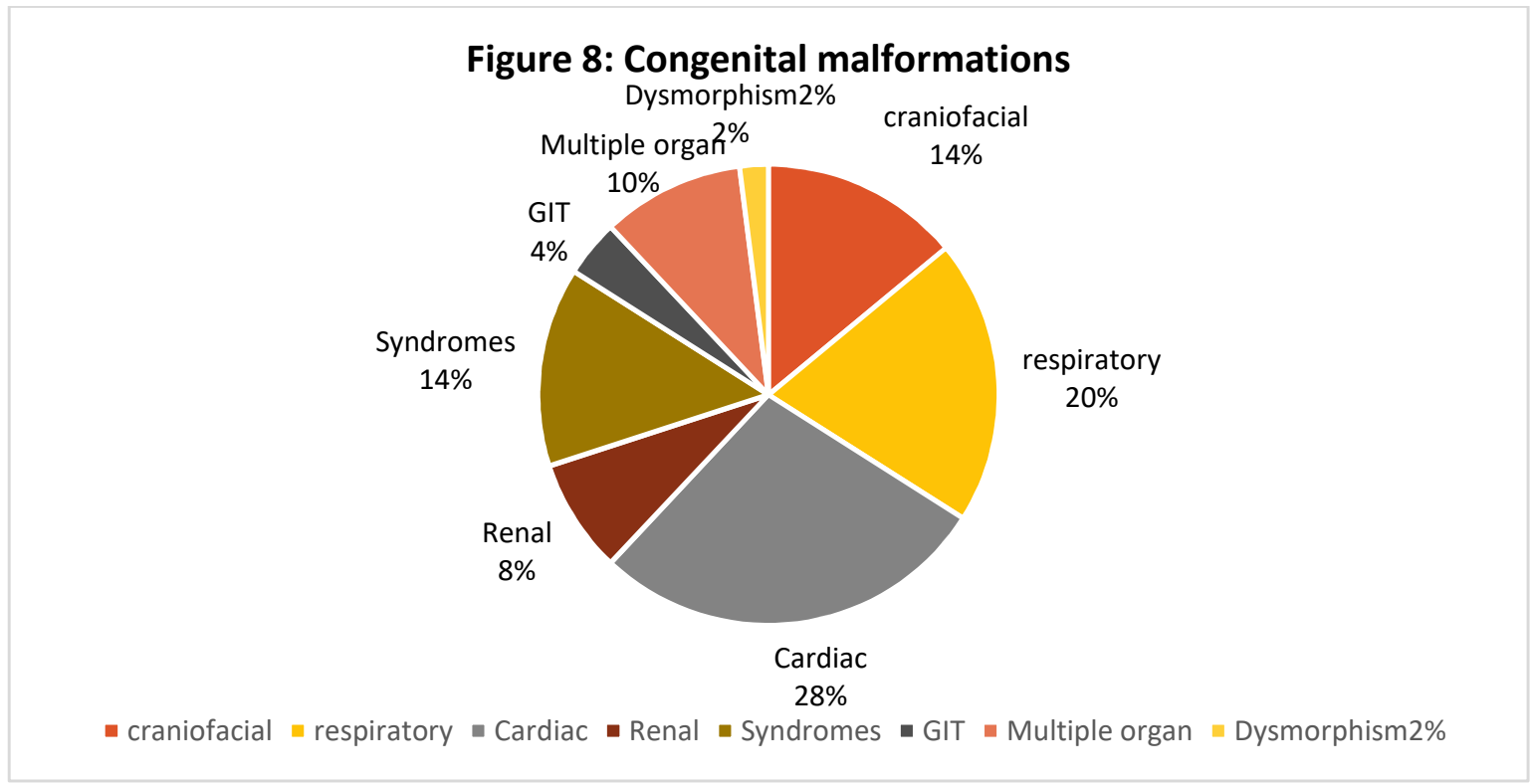

Table 4: Neonatal deaths according to birth weight versus total number of live birth in each weight category

\begin{tabular}{|c|c|c|c|c|c|c|c|c|c|c|c|c|c|c|c|c|}
\hline \multirow{2}{*}{$\begin{array}{c}\text { Birth } \\
\text { weight } \\
(\mathrm{g})\end{array}$} & \multicolumn{2}{|c|}{2010} & \multicolumn{2}{|c|}{2011} & \multicolumn{2}{|c|}{2012} & \multicolumn{2}{|c|}{2013} & \multicolumn{2}{|c|}{2014} & \multicolumn{2}{|c|}{2015} & \multicolumn{2}{|c|}{2016} & \multicolumn{2}{|c|}{207} \\
\hline & LB & $\begin{array}{l}\text { NND } \\
\text { n (\%) }\end{array}$ & LB & $\begin{array}{l}\text { NND } \\
\text { n (\%) }\end{array}$ & LB & $\begin{array}{l}\text { NND } \\
\text { n (\%) }\end{array}$ & LB & $\begin{array}{l}\text { NND } \\
\text { n (\%) }\end{array}$ & LB & $\begin{array}{l}\text { NND } \\
\text { n (\%) }\end{array}$ & LB & $\begin{array}{l}\text { NND } \\
\text { n (\%) }\end{array}$ & LB & $\begin{array}{l}\text { NND } \\
\text { n (\%) }\end{array}$ & LB & $\begin{array}{l}\text { NND } \\
\text { n (\%) }\end{array}$ \\
\hline$>2500$ & 3087 & $\begin{array}{c}4 \\
(0.1)\end{array}$ & 3327 & 0 & 3548 & $\begin{array}{c}6 \\
(0.1)\end{array}$ & 3335 & $\begin{array}{c}4 \\
(0.1)\end{array}$ & 3338 & 0 & 3138 & $\begin{array}{c}4 \\
(0.1)\end{array}$ & 3118 & $\begin{array}{c}3 \\
(0.09)\end{array}$ & 3183 & $\begin{array}{c}6 \\
(0.2)\end{array}$ \\
\hline $\begin{array}{l}1500- \\
2499\end{array}$ & 524 & $\begin{array}{c}4 \\
(0.7)\end{array}$ & 524 & 0 & 538 & $\begin{array}{c}4 \\
(0.7)\end{array}$ & 661 & $\begin{array}{c}4 \\
(0.6)\end{array}$ & 566 & $\begin{array}{c}3 \\
(0.5) \\
\end{array}$ & 454 & $\begin{array}{c}3 \\
(0.6)\end{array}$ & 453 & $\begin{array}{c}2 \\
(0.45)\end{array}$ & 512 & $\begin{array}{c}2 \\
(0.4)\end{array}$ \\
\hline $\begin{array}{l}1000- \\
1499\end{array}$ & 49 & $\begin{array}{c}5 \\
(10.2) \\
\end{array}$ & 39 & $2(5.1)$ & 54 & $\begin{array}{c}4 \\
(7.4)\end{array}$ & 38 & $\begin{array}{c}4 \\
(10.5)\end{array}$ & 32 & $\begin{array}{c}2 \\
(6.2) \\
\end{array}$ & 24 & $\begin{array}{c}1 \\
(4.1)\end{array}$ & 22 & $\begin{array}{c}1 \\
(4.5)\end{array}$ & 39 & $\begin{array}{c}4 \\
(10.2)\end{array}$ \\
\hline $\begin{array}{l}500- \\
999 \\
\end{array}$ & 14 & $\begin{array}{c}6 \\
(43) \\
\end{array}$ & 15 & $\begin{array}{c}09 \\
(60) \\
\end{array}$ & 37 & $\begin{array}{c}11 \\
(29.7)\end{array}$ & 21 & $\begin{array}{c}7 \\
(33.3)\end{array}$ & 28 & $\begin{array}{c}8 \\
(28.5) \\
\end{array}$ & 11 & $\begin{array}{c}2 \\
(18.1)\end{array}$ & 17 & $\begin{array}{c}2 \\
(11.7)\end{array}$ & 24 & $\begin{array}{c}7 \\
(29.1)\end{array}$ \\
\hline$<500$ & 0 & 0 & 0 & 0 & 2 & $\begin{array}{c}1 \\
(50)\end{array}$ & 1 & 0 & 2 & $\begin{array}{c}1 \\
(50)\end{array}$ & 0 & 0 & 1 & $\begin{array}{c}1 \\
(100)\end{array}$ & 1 & $\begin{array}{c}1 \\
1 \\
(100)\end{array}$ \\
\hline Total & 3674 & 19 & 3905 & 11 & 4179 & 26 & 4056 & 19 & 3966 & 14 & 3627 & 10 & 3611 & 09 & 3759 & 20 \\
\hline
\end{tabular}

Figure 9: Neonatal deaths in different weight groups

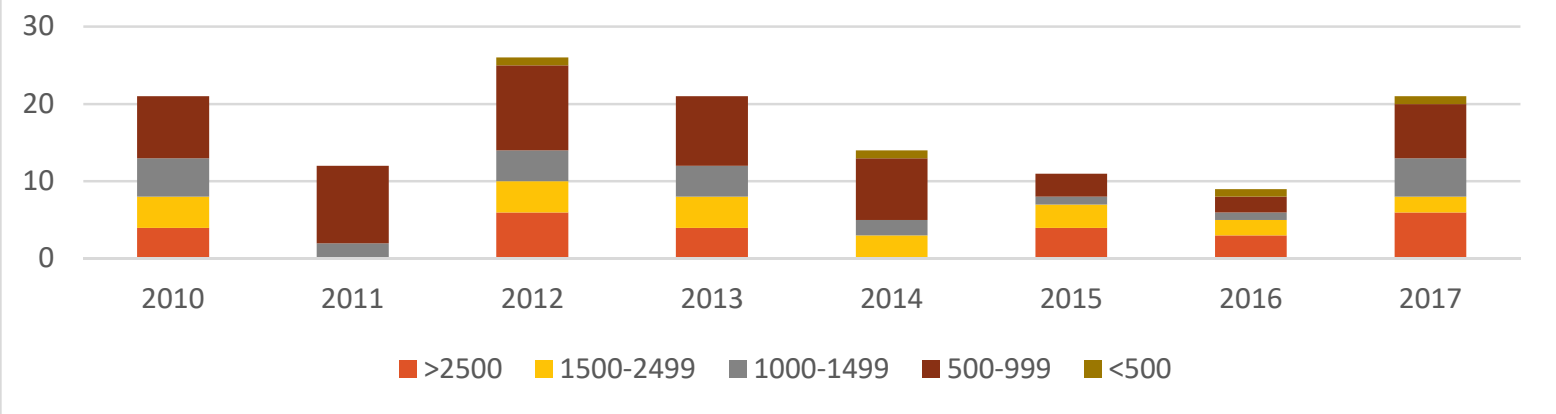

\section{Discussion}

The NMR in our institution has decreased from 2012 to 2016 and it is below the national figures throughout the study period (except in 2009). Some years, the NMR is comparable to that of developed countries. The reasons for the improvement is multifactorial and could be attributable to high female literacy, improvement in obstetric care and open access to health care facilities ${ }^{10}$. In our setting, use of advanced ventilation strategies, strict infection control measures, improvement in knowledge, skills and experience in managing preterm neonates, high numbers of resuscitation workshops held over the past years for medical and nursing officers, compulsory resuscitation workshops for pre-interns could have contributed to this success. Irrespective of the gestational age, male infants have higher biological risk of death than female infants, globally ${ }^{2}$. The same pattern was observed in our study cohort as the majority (54.1\%) of neonates who died were males.

The risk of death is greatest on the first day of life for a live born neonate ${ }^{2}$. Globally, the proportion of deaths during first day and week of life is consistent across the different regions and economical settings ${ }^{6}$. In 2012, an estimated $73 \%$ of all neonatal deaths occurred during the first week of life, with $36 \%$ ( 1 million) occurring on the first day of life ${ }^{6}$. There is no deviation of our figures from this and percentage of early neonatal deaths was $63.5 \%$ and 
first 24 hour deaths comprised $28.7 \%$ of the total deaths.

Identification of causes of deaths is a guide to implement strategies to minimise the preventable neonatal deaths and to reduce the overall infant mortality. The commonest cause of neonatal death in our study group was extreme prematurity (46.4\%). In 2012, globally, $36 \%$ of neonatal deaths were due to prematurity, $23 \%$ were due to birth asphyxia and $23 \%$ were due to sepsis ${ }^{2}$. However, there are variations between countries ${ }^{2}$. Our institutional figures indicate a higher percentage of prematurity and a much lower percentage of sepsis and asphyxia related deaths than global figures. A study conducted by S. Rajindrajith et al from 1997 to 2001 on neonatal mortality in Sri Lanka, revealed that $33.2 \%$ of deaths were due to prematurity and $7 \%$ were due to birth asphyxia ${ }^{10}$.

The second leading cause of neonatal deaths in our study was congenital malformations ( $\mathrm{n}=48,26.5 \%)$ and variation of numbers were noted over the years (Figure 7). The commonest congenital malformation was congenital heart disease and total anomalous pulmonary venous drainage, hypoplastic left heart syndrome, cardiomyopathies and congenital heart block were among them. The main respiratory cause responsible for neonatal death was lung hypoplasia secondary to diaphragmatic hernia and other causes were severe pulmonary hypertension and lung hypoplasia without diaphragmatic hernia. Out of the syndromic causes for neonatal deaths four were clinically compatible with Edward syndrome.

Interestingly, in our study group only $9.9 \%$ deaths were due to birth asphyxia which is low compared to regional and global figures ${ }^{2,10}$. In 2012, infections (pneumonia, septicaemia and meningitis) led to 0.66 million $(23 \%)$ of neonatal deaths worldwide ${ }^{2}$. In our cohort of neonates, $5 \%$ of deaths were due to proven sepsis and was lower compared to the global and national figures $(21.8 \% \text { in } 2001)^{2,10}$. The rest of the causes in decreasing order of frequency were NRDS/HMD, IVH and other (kernicterus, multiorgan failure since birth, hypotension and hydrops fetalis).

Globally, 20 million babies are born every year with low birth weight $(<2500 \mathrm{~g})$ either due to prematurity or small for gestational age (SGA) and it is one of the risk factor for higher morbidity and mortality in neonates ${ }^{2}$. Our study group was not differing from this and the highest percentage of total deaths were observed in babies born with birth weight $<1000 \mathrm{~g}$. Thus, in order to accomplish the SDG goal of reducing the low birth weight deliveries by $30 \%$ by 2025, strengthening and implementation of good obstetric care is of paramount importance.
Considering the results over the past decade, strengthening the obstetric, perinatal and neonatal care, minimising perinatal and nosocomial infections, strengthening the knowledge and practical skills of neonatal resuscitation in midwives, nurses and medical officers is of paramount importance to reduce prematurity, asphyxia and sepsis related deaths. Considering the significant contribution of congenital abnormalities towards neonatal deaths, the following can be suggested. Routine antenatal ultrasound with referral for anomaly scan when indicated should be incorporated into national obstetric guidelines. Establishing paediatric general and cardiac surgical centres in all teaching hospitals with the backing of paediatric surgical intensive care units, increasing the paediatric surgeon cadres, improving and expanding neonatal transport services will help in providing care for non-lethal neonatal abnormalities. Addressing preterm birth is the most vital aspect to accelerate the progress and to achieve the national, regional and global targets, as many deaths are due to direct complications of extreme prematurity.

\section{Conclusions}

PNMR showed a downward trend except in the last two years of the study period. The NMR is lower than the national figures and is well below the global and south Asian figures. Majority (63\%) were early neonatal deaths with $45.6 \%$ dying within the first 24 hours of birth. Leading causes of deaths were extreme prematurity, congenital malformations, respiratory distress syndrome, birth asphyxia and septicaemia.

\section{References}

1. Neonatal mortality [Internet]. World Health Organization. 2019 [cited 18 January 2019]. Available from: https://www.who.int/gho/child_health/mor tality/neonatal_text/en/

2. Lawn J, Blencowe H, Oza S, You D, Lee A, Waiswa $\mathrm{P}$ et al. Every Newborn: progress, priorities, and potential beyond survival. The Lancet 2014; 384(9938):189205.

https://doi.org/10.1016/S01406736(14)604 96-7

3. Neonatal mortality - UNICEF DATA [Internet]. UNICEF DATA. 2019 [cited 18 January 2019]. Available from: https://data.unicef.org/topic/childsurvival/ neonatal-mortality/

4. Gunawardane DA, Dharmaratne S, Rowel D. Time series analysis of neonatal 
mortality in Sri Lanka.2016. Available from:

https://www.researchgate.net/publication/ 313037169_Time_series_analysis_of_neo natal_mortality_in_Sri_Lanka

5. Child mortality estimates. Unicef Global databases. Downloaded from http://data.unicef.org

6. WHO Newborn death and illness [Internet]. Who.int. 2019 [cited 14 February 2019]. Available from: https://www.who.int/pmnch/media/press materials/fs/fs_newborndealth_illness/en/

7. Sri Lanka Every Newborn an action plan to end preventable morbidity and mortality 2017-2020. Colombo: Family Health Bureau, Ministry of Health, Sri Lanka; 2016.
Web site: www.familyhealth.gov.lk.

8. South East Asia Regional neonatal perinatal database. World Health Organization (South-East Asia Region). Working Definitions

9. Save the Children. State of the world's mothers: surviving the first day. London, UK: Save the Children International, 2013.

10. Rajindrajith S, Mettananda S, Adihetti D, Goonawardana R, Devanarayana NM. Neonatal mortality in Sri Lanka: Timing, causes and distribution. The Journal of Maternal-Fetal and Neonatal Medicine. 2009; 22(9): 791-6. https://doi.org/10.3109/147670509029945 49

PMid: 19526423 